\title{
Characteristics and surgical outcomes of cleft palate in kabuki syndrome: a case series of 11 patients
}

\author{
Jong-Ho Kim, Jiwon Kang, Joon Seok Oh, Taeseon Ahn, Baek-kyu Kim and Rong-Min Baek
}

\begin{abstract}
Objective: A significant number of patients with KS have cleft palate (CP) or submucous cleft palate (SMCP) and show delayed speech development. However, few reports have discussed the characteristics of CP in KS and the outcomes of postoperative speech development. The purpose of this study was to investigate the characteristics and surgical outcomes of CP in patients with KS, and to discuss the importance of the diagnosis of CP or SMCP.

Methods: We conducted a retrospective study on patients with clinically diagnosed KS who underwent palatoplasty. Clinical and surgical data were collected from patients' medical records, and velopharyngeal function was evaluated using nasopharyngoscopy and speech analysis.

Results: In 11 cases, 5 patients had CP (45.5\%) and 6 had SMCP (54.5\%). Four patients who were genetically tested had a pathogenic variant of KMT2D. Seven of nine patients (77.8\%) who underwent conventional palatoplasty showed velopharyngeal insufficiency and hypernasality. All patients who underwent pharyngeal flap surgery achieved velopharyngeal competency. Statistical analysis revealed a statistically significant difference in postoperative results between non-syndromic and KS patients.

Conclusion: Patients with SMCP may be more common than previously reported. The results showed that it is difficult to produce optimal results with conventional palatoplasty; therefore, pharyngeal flap surgery should be considered as a treatment to obtain favorable results. Pharyngeal flap surgery in patients with KS should be carefully designed based on speech evaluation and nasopharyngoscopic findings.
\end{abstract}

Keywords: Kabuki syndrome, Cleft palate, Pharyngeal flap surgery

\section{Introduction}

Kabuki syndrome (KS [MIM: 147920 and 300,867]), first reported by Niikawa et al., is a syndrome of multiple congenital anomalies [1]. Niikawa et al. suggested the term "Kabuki make-up syndrome" due to the characteristic facial features resembling the make-up worn in the traditional Japanese play "Kabuki". A clinical diagnosis based on unique facial features, as reported by Niikawa

\footnotetext{
*Correspondence: ronbaek@snu.ac.kr

Department of Plastic and Reconstructive Surgery, Seoul National University College of Medicine, Seoul National University Bundang Hospital, 82 Gumi-ro 173beon-gil, Bundang-gu, Seongnam 463-707, South Korea
}

and Kuroki, is the most commonly used diagnostic tool [2]. The facial features of patients with KS include long palpebral fissures with slight ectropion of the lateral third of the lower eyelid and sparse lateral eyebrows [3]. In addition, patients with KS show a variable range of abnormalities including mild mental retardation, hearing difficulty, cardiac anomaly, and skeletal instability. In 2010 and 2012, pathogenic variants of lysine-specific methyltransferase 2D (KMT2D) and lysine-specific demethylase 6A (KDM6A) were reported to cause KS [4, 5]. As gene mutations became a critical diagnostic tool, new diagnostic criteria were suggested [6]. Based on

(c) The Author(s). 2021 Open Access This article is licensed under a Creative Commons Attribution 4.0 International License, which permits use, sharing, adaptation, distribution and reproduction in any medium or format, as long as you give appropriate credit to the original author(s) and the source, provide a link to the Creative Commons licence, and indicate if changes were made. The images or other third party material in this article are included in the article's Creative Commons licence, unless indicated otherwise in a credit line to the material. If material is not included in the article's Creative Commons licence and your intended use is not permitted by statutory regulation or exceeds the permitted use, you will need to obtain permission directly from the copyright holder. To view a copy of this licence, visit http://creativecommons.org/licenses/by/4.0/ The Creative Commons Public Domain Dedication waiver (http://creativecommons.org/publicdomain/zero/1.0/) applies to the data made available in this article, unless otherwise stated in a credit line to the data. 
these criteria, the authors suggested two major diagnostic criteria: pathogenic variants in KMT2D or KDM6A and typical dysmorphic features. Typical dysmorphic features include long palpebral fissures with eversion of the lateral third of the lower eyelid and two or more of the following: (1) arched and broad eyebrows with the lateral third displaying notching or sparseness; (2) short columella with depressed nasal tip; (3) large, prominent or cupped ears; and (4) persistent fingertip pads. Heterozygous mutations in $K M T 2 D$ have been identified in approximately $60-70 \%$ of Patients with KS and mutations in KDM6A account for $5-8 \%$ of patients with KS [7]. Both genes encode for proteins that affect the epigenetic regulation of transcriptionally active chromatin by interacting with each other in the protein complex [8]. A significant number of patients with KS have cleft palate (CP) or submucous cleft palate (SMCP) and show delayed speech development [9]. Although the etiologic roles of both mutations have been proposed in the function of several organs, evidence of the involvement of these genes in oro-pharyngeal development is very limited. Niikawa et al. [1] reported the prevalence of CP in
KS as 33\% and Schrander-Stumpel et al. [10], reported that $50 \%$ of patients with KS had CP or bifid uvula. Although Lida et al. [11] reported six patients with KS with $\mathrm{CP}$, few reports have discussed the characteristics of $\mathrm{CP}$ in $\mathrm{KS}$ and the outcomes of postoperative speech development. The purpose of this study is to investigate the characteristics and surgical outcomes of $\mathrm{CP}$ in patients with KS, and to discuss the importance of proper diagnosis of CP or SMCP and the determination of the surgical method.

\section{Methods}

This study was approved by the Institutional Review Board of the committee of Seoul National University Bundang Hospital (Number:B-2103/673-108). Informed consent to publish from legally authorized representative of the minor for Fig. 1 has been obtained. We conducted a retrospective study on patients with KS previously examined in the Department of Plastic and Reconstructive Surgery and the Department of Pediatrics of Seoul National University Bundang Hospital between 2003 and 2019. All patients were clinically diagnosed using

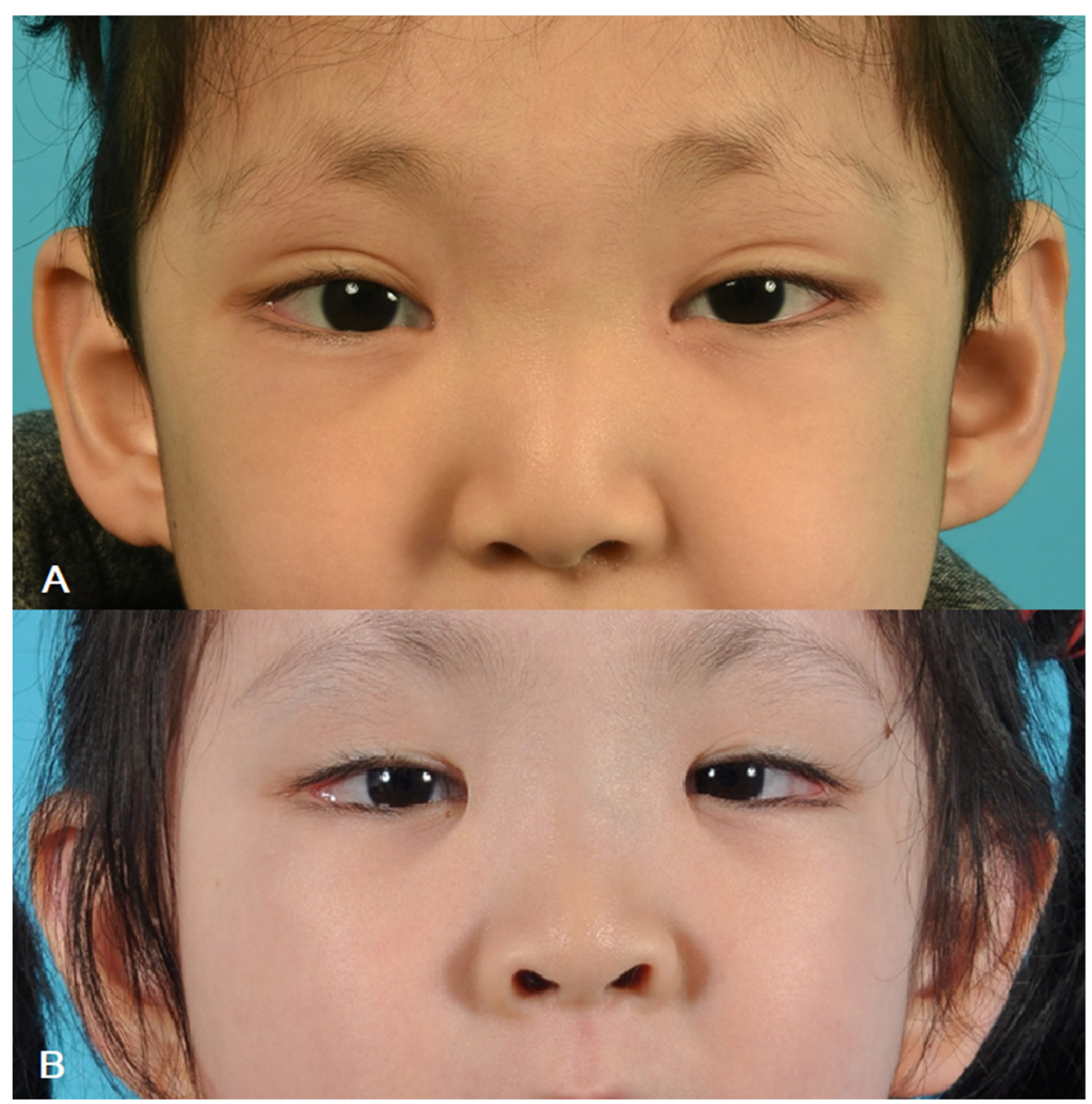

Fig. 1 Facial appearance with long palpebral fissure, arched and broad eyebrows, and depressed nose 
diagnostic criteria [6] and genetically diagnosed patients were recorded. (Fig. 1) Patients who did not undergo surgery or who were lost to follow-up were excluded. The clinical data and surgical outcomes of 11 patients were collected from the patients' medical records. Velopharyngeal function was evaluated using nasopharyngoscopy and speech analysis. Postoperative results were assessed by speech evaluation which was performed by the speech pathologist (Ahn) and the presence of velopharyngeal insufficiency (VPI), including remaining hypernasality (grade $>1$ by Henningsson rating system) was evaluated. To investigate the correlation between postoperative speech outcomes and the presence of KS, statistical analysis using Fisher's exact test was performed with patients who had previously operated nonsyndromic CP and SCMP in our institute $[12,13]$. A $p$ value $\leq 0.05$ was considered statistically significant. All statistical analyses were performed using SPSS version 22.0 (SPSS Inc., Chicago, IL).

\section{Palatoplasty methods}

Double opposing $\mathrm{Z}$ plasty (DOZ) and limited incision with thorough elevation (LITE) palatoplasty were used for correction of CP. The primary surgical procedure was performed when the patients were approximately 12-18 months of age. In cases of $\mathrm{CP}$ patients for whom preoperative evaluation was impossible, palatoplasty method was decided according to the surgical protocol of our institute. LITE was performed when the cleft gap was greater than $1 \mathrm{~cm}$ or the complete type, and DOZ was performed when the cleft gap was less than $1 \mathrm{~cm}$. In cases of SMCP or VPI following primary palatoplasty, DOZ and posterior pharyngeal flap (PPF) were used for correction when the patient reached the age of cooperating with nasopharyngoscopy,. The surgical method was comprehensively determined based on the results of speech evaluation and nasopharyngoscopy.

DOZ was performed as described by Furlow with slight modifications [14]. Intraoperatively, all abnormally inserted levator veli palatine muscles were fully released and anatomical reconstruction was achieved. As per our modification, the extent of muscular dissection was greater than that described by Furlow, which released all abnormal insertions along the posterior border of the hard palate [12]. LITE is a modified two-flap palatoplasty that limits the incision at the anterior hard palate and elevates the movable palatal flap with thorough dissection over the entire palate [13]. DOZ or LITE was considered to be ineffective when the results of speech evaluation and nasopharyngoscopy showed that the palatal muscle was incompetent, and PPF was performed to create an anatomical barrier between the oral cavity and the nasal cavity to reduce nasal emission [15]. The PPF procedure involves elevation of a superior-based myomucosal flap and insertion into the soft palate to create a static sling and overcome the VPI.

\section{Speech evaluation}

An experienced speech pathologist (Ahn) performed standardized speech evaluation for these patients. Perceptual speech evaluation was performed using the universal parameters and rating system described by Henningsson which consists of hypernasality, hyponasality, nasal emission, articulation errors, and intelligibility [16]. In addition to perceptual assessment, nasalance score, which is a ratio between oral and nasal acoustic energy, was obtained using Nasometer II 6400 (KAYP ENTAX, Montvale, NJ). The nasometry was used as a supplementary tool in patients with hypernasality in speech evaluation, where it was used to aid in the interpretation of the results of hypernasality For all parameters, a score of 0 indicated that, within normal limits, there was no deviation from present perception.

\section{Nasopharyngoscopy}

Nasopharyngoscopy was performed in VPI patients after the first palatoplasty and SMCP patients who were cooperative, usually $>4$ years. A flexible fiberoptic endoscope was inserted for evaluation of velopharyngeal motility and visualization of the anatomy under various conditions and phonations. VPI was evaluated by closure of the velopharyngeal port during phonation [15]. To determine the surgical plan preoperatively, or to evaluate postoperative outcomes, the size of the central gap was measured with the lateral pharyngeal walls maximally contracted to the velopharyngeal port. The size of the central gap and the symmetry of lateral pharyngeal wall movement were recorded while the patients repetitively pronounced oral and nasal pressure-loaded words. The size of the central gap was classified into six categories. 0 , closure; 1 , touch closure (pinhole); 2 , small (close $\geq 80 \%$ of the resting gap); 3 , intermediate (close to 50 $80 \%$ of the resting gap); 4 , large (close to $<50 \%$ of the resting gap); and 5, hypodynamic velopharynx]. The lateral pharyngeal wall movement was categorized as either symmetric or asymmetric. The velopharyngeal closure pattern was classified into four categories as follows: 1 , coronal; 2, circular; 3 , sagittal; and 4, bow tie. If the postoperative speech outcome was within normal limits in follow-up period, no additional nasopharyngoscopy was performed.

\section{Results}

Sex, type of CP, combined congenital anomalies, and clinical characteristics, including major diagnostic criteria are summarized in Table 1. The included patients comprised five men (45.5\%) and six women (54.5\%) and the mean follow-up period was 5 years 7 months $(2$ years 
Table 1 Clinical characteristics of patients

\begin{tabular}{|c|c|c|c|c|c|c|c|c|c|}
\hline \multirow[t]{2}{*}{ 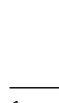 } & \multirow[t]{2}{*}{ Sex } & \multirow[t]{2}{*}{ Type } & \multicolumn{5}{|c|}{ Major diagnostic criteria } & \multirow{2}{*}{$\begin{array}{l}\text { Genetic } \\
\text { diagnosis }\end{array}$} & \multirow[t]{2}{*}{ Other congenital anomalies } \\
\hline & & & (1) & $(2)$ & (3) & (4) & (5) & & \\
\hline 1 & $\mathrm{~F}$ & $\mathrm{CP}$ & $\mathrm{O}$ & $\mathrm{O}$ & $\mathrm{O}$ & $\mathrm{O}$ & $\mathrm{O}$ & - & VSD \\
\hline 2 & M & $C P$ & $\mathrm{O}$ & $\mathrm{O}$ & $\mathrm{O}$ & $\mathrm{O}$ & $\mathrm{O}$ & - & \\
\hline 3 & $\mathrm{~F}$ & $C P$ & $\mathrm{O}$ & $\mathrm{O}$ & $\mathrm{O}$ & $\mathrm{O}$ & $\mathrm{O}$ & - & ASD / Blepharoptosis, Rt. \\
\hline 4 & M & $\mathrm{CP}$ & $\mathrm{O}$ & $\mathrm{O}$ & $\mathrm{O}$ & $\mathrm{O}$ & $\mathrm{O}$ & - & ASD / Scoliosis \\
\hline 5 & M & $C P$ & $\mathrm{O}$ & $\mathrm{O}$ & $x$ & $\mathrm{O}$ & $\mathrm{O}$ & O (KMT2D) & \\
\hline 6 & M & SMCP & O & O & O & $\mathrm{O}$ & $\mathrm{O}$ & - & \\
\hline 7 & $\mathrm{~F}$ & SMCP & $\mathrm{O}$ & $\mathrm{O}$ & $\mathrm{O}$ & $x$ & $\mathrm{O}$ & - & \\
\hline 8 & $\mathrm{~F}$ & SMCP & $\mathrm{O}$ & $\mathrm{O}$ & $\mathrm{O}$ & $\mathrm{O}$ & $\mathrm{O}$ & O (KMT2D) & Strabismus \\
\hline 9 & $\mathrm{~F}$ & SMCP & $\mathrm{O}$ & $\mathrm{O}$ & O & $\mathrm{O}$ & $\mathrm{O}$ & O (KMT2D) & Strabismus \\
\hline 10 & $\mathrm{~F}$ & SMCP & O & $\mathrm{O}$ & $x$ & $\mathrm{O}$ & $\mathrm{O}$ & - & \\
\hline 11 & M & SMCP & $\mathrm{O}$ & $\mathrm{O}$ & $\mathrm{O}$ & $x$ & $\mathrm{O}$ & O (KMT2D) & Hypothyroidism, Horseshoe kidney \\
\hline
\end{tabular}

Major diagnostic criteria

(1) long palpebral fissures with eversion of the lateral third of the lower eyelid

(2) arched and broad eyebrows with the lateral third displaying notching or sparseness

(3) short columella with depressed nasal tip

(4) large, prominent or cupped ears

(5) finger fat pads

$C P$ Cleft palate, SMCP Submucous cleft palate, VSD Ventricular septal defect, ASD Atrial septal defect)

to 11 years and 2 months). Four patients were genetically tested, and all were found to have pathogenic variants of $K M T 2 D$. For the other seven patients with KS, genetic tests were not performed due to parental refusal. Five patients had CP (45.5\%) and six patients had SMCP (54.5\%). All patients with $\mathrm{CP}$ were of incomplete type, and incomplete clefts of three patients (cases 1,2, and 5) involved hard and soft palates. The other two patients (cases 3 and 4) had clefts involving only the soft palate. All patients with SMCP had the classic triad of bifid uvula, hard palate bony notch, and zona pellucida of the soft palate (Fig. 2).

The surgical methods, age at surgery, results of preoperative and postoperative speech evaluation, and nasopharyngoscopic findings are summarized in Table 2 . Preoperative nasopharyngoscopic findings revealed an

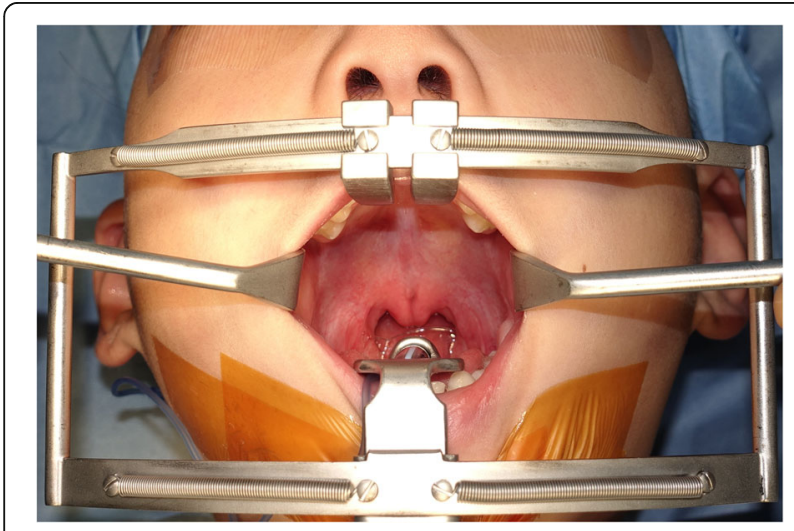

Fig. 2 Intraoperative photo. Submucous cleft palate with bifid uvula and zona pellucida average central gap size of 3.1 points. Of the five patients with $\mathrm{CP}$, three patients underwent LITE palatoplasty and two patients underwent DOZ palatoplasty. Four patients (cases 1,3,4 and 5) were unable to achieve velopharyngeal competency and had remaining hypernasality at postoperative follow-up. Among the four patients with SMCP who underwent DOZ palatoplasty, only one patient achieved velopharyngeal competency. Intraoperatively, muscular deficiency was identified in all patients who underwent palatoplasty. Two of the patients with SMCP underwent PPF as the first operation and five patients (three patients with $\mathrm{CP}$ and two patients with SMCP) underwent PPF as the second operation. All seven patients who underwent PPF operation achieved velopharyngeal competency. In previous studies conducted by our institute, in non-sydromic patients, 54 of 56 patients with CP $(96.4 \%)$ and 54 of 64 patients with SMCP (84.3\%) obtained velopharyngeal competency. Fisher's exact test showed statistically significant difference in postoperative results between non-syndromic and KS patients. In patients with CP and SMCP, the $p$ values were $<0.001$ and 0.02 , respectively, and these results showed that surgical outcomes were poor in patients with KS (Table 3.)

\section{Discussion}

\section{Characteristics of $\mathrm{CP}$ and diagnosis of submucous $\mathrm{CP}$ in KS}

Handa et al. reviewed patients with KS with cleft lip, CP and SMCP, and reported that $41 \%$ of these patients had cleft lip and palate [17]. Niikawa et al. reported that 23 of 56 patients with $\mathrm{KS}$ have $\mathrm{CP} /$ lip including isolated 
Table 2 Palatoplasty, Speech evaluation and Nasopharyngoscopy results

\begin{tabular}{|c|c|c|c|c|c|c|c|c|}
\hline & \multirow[t]{2}{*}{ Sex } & \multirow[t]{2}{*}{ Type } & \multicolumn{2}{|c|}{ Operation (Age at operation, in years and months) } & \multirow{2}{*}{$\begin{array}{l}\text { Preoperative } \\
\text { Nasopharyngoscopy }\end{array}$} & \multicolumn{3}{|c|}{ Speech evaluation } \\
\hline & & & $1 \mathrm{st}$ & 2nd & & Pre (1st) & Pre(2nd) & Post \\
\hline 1 & $\mathrm{~F}$ & $C P$ & LITE (1y3m) & $(-)$ & $(-)$ & $(-)$ & $(-)$ & $2 / 0 / 2 / 1 / 2$ \\
\hline 2 & M & $C P$ & LITE (1y6m) & $(-)$ & $(-)$ & $(-)$ & $(-)$ & $1 / 0 / 2 / 1 / 1$ \\
\hline 3 & $\mathrm{~F}$ & $C P$ & LITE (1y6m) & $\operatorname{PPF}(7 y 6 \mathrm{~m})$ & $4 / 1 / 1$ & $(-)$ & $3 / 0 / 2 / 1 / 2$ & $1 / 0 / 2 / 1 / 1$ \\
\hline 4 & M & $C P$ & DOZ (1y8m) & PPF (6y8m) & $2 / 1 / 3$ & $(-)$ & $2 / 0 / 1 / 1 / 2$ & $0 / 0 / 1 / 1 / 2$ \\
\hline 5 & M & $C P$ & DOZ (1y5m) & PPF (5y6m) & $3 / 1 / 2$ & $(-)$ & $2 / 0 / 2 / 1 / 2$ & $0 / 0 / 0 / 1 / 1$ \\
\hline 6 & M & SMCP & DOZ (5y12m) & $\operatorname{PPF}(7 y 3 m)$ & $4 / 1 / 2$ & $3 / 0 / 2 / 1 / 2$ & $2 / 0 / 2 / 1 / 2$ & $0 / 0 / 0 / 1 / 0$ \\
\hline 7 & $\mathrm{~F}$ & SMCP & DOZ (5y11m) & $\operatorname{PPF}(7 y 2 m)$ & $3 / 1 / 2$ & $3 / 0 / 2 / 1 / 1$ & $2 / 0 / 2 / 1 / 1$ & $1 / 0 / 2 / 1 / 1$ \\
\hline 8 & $\mathrm{~F}$ & SMCP & DOZ (5y10m) & $(-)$ & $2 / 1 / 2$ & $3 / 0 / 2 / 1 / 2$ & $(-)$ & $2 / 0 / 2 / 1 / 2$ \\
\hline 9 & $\mathrm{~F}$ & SMCP & DOZ (6y5m) & $(-)$ & $4 / 1 / 2$ & $2 / 0 / 2 / 1 / 2$ & $(-)$ & $0 / 0 / 2 / 1 / 2$ \\
\hline 10 & $\mathrm{~F}$ & SMCP & PPF (6y1m) & $(-)$ & $3 / 1 / 2$ & $2 / 0 / 2 / 1 / 2$ & $(-)$ & $0 / 0 / 0 / 1 / 0$ \\
\hline 11 & M & SMCP & PPF (5y10m) & $(-)$ & $3 / 1 / 2$ & $2 / 0 / 1 / 1 / 2$ & $(-)$ & 0/0/1/1/0 \\
\hline
\end{tabular}

Speech evaluation: hypernasality / hyponasality / nasal emission / articulation errors / intelligibility

Preoperative nasopharyngoscopy: Opening size / Symmetry / Pattern (1, coronal; 2, circular; 3, sagittal; 4, bow tie)

CP Cleft palate, SMCP Submucous cleft palate, LITE Limited incision thorough elevation palatoplasty, PPF Posterior pharyngeal flap, DOZ Double opposing Z-plasty

CP, isolated cleft lip and CP with cleft lip [1]. However, Burke and Jones [18] and Schrander-Stumpel et al. [10] reported that all of patients with $\mathrm{KS}$ with $\mathrm{CP}$ were of the isolated CP type. In our study, all patients had isolated CP or SMCP without cleft lip or alveolar cleft. Clinical findings, such as gap size and hard palate involvement, were not significantly different from those of other nonsyndromic patients with CP. Four genetically diagnosed patients had a heterozygous pathogenic variant of $K M T 2 D$, which was consistent with the results of previous studies showing $\mathrm{CP}$ was more associated with the KMT2D gene [6]. Previous studies reported that most patients with $\mathrm{CP}$ and $\mathrm{KS}$ have pathogenic variants in $K M T 2 D$, which may also be related to increase feeding problems, speech delays, and orodental defects [19]. To date, only one case series by Lida et al. examined the SMCP of patients with KS [11]. They reported that 6 patients had CP and 3 of 6 (50\%) had SMCP. Moreover, they suggested that mental retardation, which is often accompanied by KS [20], is an obstacle for diagnosing SMCP because delayed speech development could be also attributed to be caused due to mental retardation.

Table 3 Statistical analysis (Fisher's exact test performed by SPSS version 22.0)

\begin{tabular}{llll}
\hline Group & HN(-) & HN (+) & p-value \\
\hline CP & 54 & 2 & $<0.001$ \\
$\quad$ Non-syndromic & 1 & 4 & \\
$\quad$ Kabuki & & & 0.02 \\
SMCP (DOZ) & 54 & 10 & \\
$\quad$ Non-syndromic & 1 & 3 & \\
Kabuki & & & \\
\hline
\end{tabular}

HN Hypernasality
There have been no large studies on the proportion of SMCP in patients with KS. This study is the first report describing association of a pathogenic variant of KMT2D with SMCP in patients with KS. In this study, 6 of 11 patients (54.5\%) had SMCP, all of whom were referred for delayed speech development. Among the six patients, five were not diagnosed with KS at birth. Three genetically diagnosed patients with SMCP had a heterozygous pathogenic variant of $K M T 2 D$. KS is difficult to diagnose in neonates and infants because their facial features are not as obvious as those of older children [3]. One of these patients (case 8), despite being diagnosed with KS in another hospital, was not suspected to have SMCP for delayed speech development. Based on these results, it is important to consider that there is a higher possibility of SMCP in KS than previously reported. Further studies will be needed on the incidence of SMCP in patients with KS with a pathogenic variant of KMT2D.

\section{Delayed speech development in KS}

A considerable number of patients with KS show delayed speech development [9]. Mental retardation or cognitive delays are a common characteristic of patients with KS and these features are important causes of delayed speech development in patients with KS. Upton et al. [21] suggested that speech delay appeared to be due to poor coordination and oral-motor hypotonia, not structural abnormalities. However, as mentioned above, there is a possibility that an underdiagnosed SMCP in patients with KS is an obstacle to speech development. Therefore, the speech developmental delay in patients with KS appears to be due to various factors including mental retardation, oral-motor hypotonia, and undiagnosed SMCP [22, 23]. In our series, case 4 had mental 
retardation and it was difficult to evaluate a certain cause of delayed speech development. Although there is a limit to improving intelligibility or expression skills, speech problems resulting from structural abnormalities, such as hypernasality, can be corrected by proper operation. Therefore, to evaluate the speech development of patients with KS, it is essential to distinguish between a pure delay of speech development and a delay combined with SMCP through precise speech evaluation of hypernasality, nasal emission, articulation error and intelligibility [24]. If corrective surgery is appropriately performed, especially in patients with a normal range of intelligence or mild mental retardation, there can be considerable improvement in language development (cases 6 and 8).

\section{Preoperative evaluation and determination of surgical methods}

In addition to speech evaluation, nasopharyngoscopy was performed on all patients with SCMP and CP who underwent a second surgery for velopharyngeal insufficiency correction. Other imaging studies, such as videofluoroscopy, also represent good tools for diagnosis [25, 26]. In preoperative planning, especially planning for PPF surgery, the size of the flap needs to be accurately measured and correctly designed to fill the central velopharyngeal gap. Although operator proficiency and patient cooperation are required, nasopharyngoscopy is the best tool for preoperative planning (Fig. 3). Compared to the results in our institute $[12,13]$, patients with $\mathrm{CP}$ or SMCP who underwent palatoplasty showed unsatisfactory results, such as persistent hypernasality, which was also statistically significant (Table 3). Based on these results, it is assumed that the postoperative results of patients with KS are not satisfactory compared to patients who had similar degrees of severity in preoperative findings. Therefore, as poor outcomes have been reported with conventional palatoplasty in other syndromic patients [27-29], it is also necessary to consider the possibility of unsatisfactory results due to factors separate from mental retardation in patients with KS. Antonio et al. reported that DOZ palatoplasty produced satisfactory results in non-syndromic patients but poor results in the velocardiofacial syndrome (VCFS) group; of the four reviewed patients, none had adequate velopharyngeal closure [28]. Chegar et al. [30] reported that pharyngeal flap surgery was the most effective treatment for patients with VCFS who had velopharyngeal insufficiency with hypernasal resonance. Case 11 had an intermediate opening size, for which the PPF was not considered when compared to previous conventional cases. However, the PPF surgery was performed based on speech evaluation, movement of the palate on nasopharyngoscopy and experience of the previous KS cases, and satisfactory results were achieved. Park et al. [31] reported that the thickness of the levator veli palatini muscle in patients with VCFS was significantly lower than that in non-syndromic patients with SMCP. We observed a similar deficiency of levator veli palatini muscle intraoperatively in patients with KS (Fig. 4). This could be a contributing factor to suboptimal results after surgical correction and further studies should follow. The surgeon must keep in mind that it is difficult to produce optimal results with conventional palatoplasty in the absence of muscular structure, and this should be clearly explained to the parents of the patients. All seven patients who underwent pharyngeal flap surgery (cases $3-7,10$, and 11) showed satisfactory results. Therefore, although palatoplasty is performed to close the nasal and oral cavity in cases of congenital $\mathrm{CP}$, it is important to be aware that there is a high possibility of velopharyngeal insufficiency and pharyngeal flap surgery should be considered as proper treatment in patients with KS.

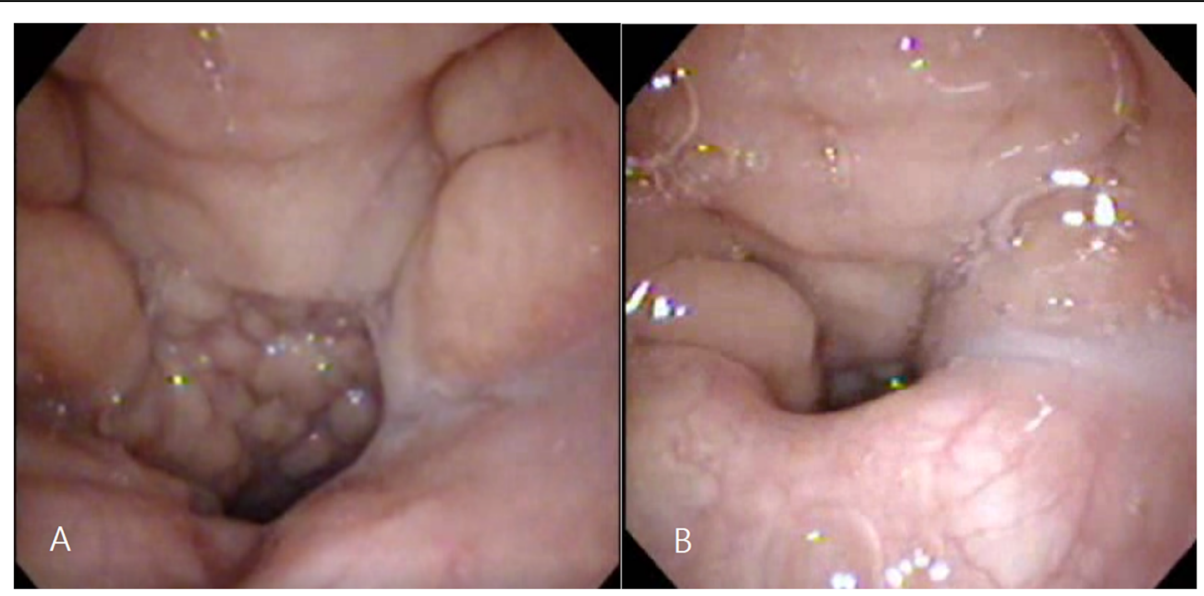

Fig. 3 Measuring the size of central gap with nasopharyngoscopy. Velopharyngeal port on Resting state (left) and Maximally contracted state (right) 


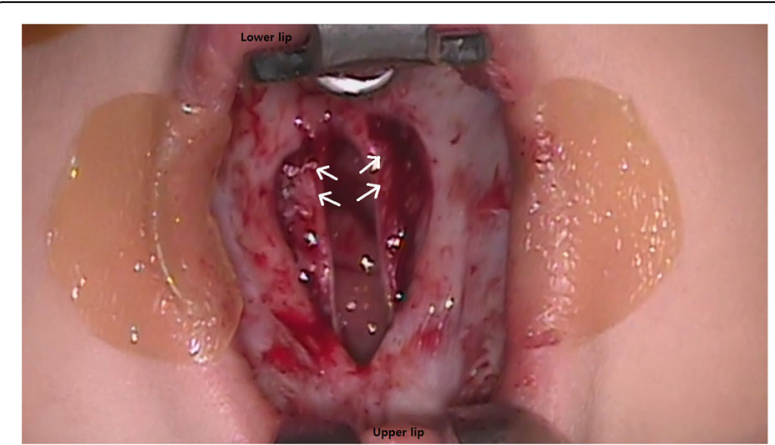

Fig. 4 Intraoperative photo showing deficiency of the levator veli palatini muscle (white arrows)

\section{Conclusion}

The results of this study suggest that there are more cases of SMCP in patients with KS than previously reported, and SMCP should be considered when this patient group present with speech problems. We also observed deficiency of the levator veli palatini muscle, which made it difficult to produce optimal results with conventional palatoplasty in patients with KS. Therefore, pharyngeal flap surgery should be considered as a proper treatment to obtain favorable results and this method should be carefully designed based on speech evaluation and nasopharyngoscopic findings.

\section{Abbreviations}

KS: Kabuki syndrome; CP: cleft palate; SMCP: Submucous cleft palate; DOZ: Double opposing Z plasty; LITE: Limited incision with thorough elevation; VPI: Velopharyngeal insufficiency; PPF: Posterior pharyngeal flap; VCFS: Velocardiofacial syndrome

\section{Supplementary Information}

The online version contains supplementary material available at https://doi. org/10.1186/s12887-021-02852-4.

Additional file 1: Supplementary material 1. Nasopharyngoscopic finding. A flexible fiberoptic endoscope was inserted for evaluation of velopharyngeal motility and visualization of the anatomy under various conditions and phonations. This patient with kabuki syndrome showed velopharyngeal insufficiency associated with hypernasality and intermediate size of central gap.

\section{Acknowledgements}

None.

\section{Authors' contributions}

All authors have read and approved the manuscript. a. Designing: JHK, BKK, RMB b. Coordinating: JK, TA c. Literature search: JK, JSO, TA d. Quality assessment: JK, BKK e. Data analysis: JK, JSO. f. Data interpretation: JHK, JK, JSO g. Writing: JHK, JK RMB.

\section{Funding}

There was no payment, grant or honorarium given to anyone to produce the research/manuscript.

\section{Availability of data and materials}

Data has been anonymized and is kept with the authors. Datasets are available from the corresponding author on reasonable request.

\section{Declarations}

Ethics approval and consent to participate

This study was approved from Ethics Committee (IRB no.: B-2103/673-108) in the Seoul National University Bundang hospital. Written informed consent to participate was obtained from all participants' parents. All methods were carried out in accordance with relevant guidelines and regulations under Ethics approval and consent to participate.

\section{Consent for publication}

Informed consent to publish from legally authorized representative of the minor for Fig. 1 has been obtained.

\section{Competing interests}

The authors declare that they have no competing interests.

Received: 23 March 2021 Accepted: 24 August 2021

Published online: 03 September 2021

\section{References}

1. Niikawa N, Matsuura N, Fukushima Y, Ohsawa T, Kajii T. Kabuki make-up syndrome: a syndrome of mental retardation, unusual facies, large and protruding ears, and postnatal growth deficiency. J Pediatr. 1981;99(4):5659. https://doi.org/10.1016/S0022-3476(81)80255-7.

2. Kuroki Y, Suzuki Y, Chyo H, Hata A, Matsui I. A new malformation syndrome of long palpebral fissures, large ears, depressed nasal tip, and skeletal anomalies associated with postnatal dwarfism and mental retardation. J Pediatr. 1981;99(4):570-3. https://doi.org/10.1016/S0022-3476(81)80256-9.

3. Wang YR, Xu NX, Wang J, Wang XM. Kabuki syndrome: review of the clinical features, diagnosis and epigenetic mechanisms. World J Pediatr. 2019;15(6): 528-35. https://doi.org/10.1007/s12519-019-00309-4.

4. Ng SB, Bigham AW, Buckingham KJ, Hannibal MC, McMillin MJ, Gildersleeve $\mathrm{HI}$, et al. Exome sequencing identifies MLL2 mutations as a cause of kabuki syndrome. Nat Genet. 2010;42(9):790-3. https://doi.org/10.1038/ng.646.

5. Lederer D, Grisart B, Digilio MC, Benoit V, Crespin M, Ghariani SC, et al. Deletion of KDM6A, a histone demethylase interacting with MLL2, in three patients with kabuki syndrome. Am J Hum Genet. 2012;90(1):119-24. https://doi.org/10.1016/j.ajhg.2011.11.021.

6. Adam MP, Banka S, Bjornsson HT, Bodamer O, Chudley AE, Harris J, et al. Kabuki syndrome: international consensus diagnostic criteria. J Med Genet. 2019;56(2):89-95. https://doi.org/10.1136/jmedgenet-2018-105625.

7. Bögershausen N, Gatinois V, Riehmer V, Kayserili H, Becker J, Thoenes M, et al. Mutation update for kabuki syndrome genes KMT2D and KDM6A and further delineation of X-linked kabuki syndrome subtype 2. Hum Mutat. 2016;37(9):847-64. https://doi.org/10.1002/humu.23026.

8. Lintas C, Persico AM. Unraveling molecular pathways shared by kabuki and kabuki-like syndromes. Clin Genet. 2018;94(3-4):283-95. https://doi.org/1 $0.1111 /$ cge.12983.

9. Morgan AT, Mei C, Da Costa A, Fifer J, Lederer D, Benoit V, et al. Speech and language in a genotyped cohort of individuals with kabuki syndrome. Am J Med Genet A. 2015;167(7):1483-92. https://doi.org/10.1002/ajmg.a.37026.

10. Schrander-Stumpel CT, Spruyt L, Curfs LM, Defloor T, Schrander JJ. Kabuki syndrome: clinical data in 20 patients, literature review, and further guidelines for preventive management. Am J Med Genet A. 2005;132A(3): 234-43. https://doi.org/10.1002/ajmg.a.30331.

11. Iida T, Park S, Kato K, Kitano I. Cleft palate in kabuki syndrome: a report of six cases. Cleft Palate Craniofac J. 2006;43(6):756-61. https://doi.org/10.1597/ 05-174.

12. Baek RM, Kim BK, Jeong JH, Ahn T, Park M, Han J. The effect of age at surgery and compensatory articulation on speech outcome in submucous cleft palate patients treated with double-opposing Z-plasty: a 10-year experience. J Plast Reconstr Aesthet Surg. 2017;70(5):646-52. https://doi. org/10.1016/j.bjps.2016.12.025.

13. Baek RM, Koo YT, Kim BK. Limited incision with thorough elevation palatoplasty: technical evolution for superior results in cleft repair of the secondary palate. Ann Plast Surg. 2015;74(2):187-90. https://doi.org/10.1097/ SAP.0b013e31829565d8.

14. Furlow LT Jr. Cleft palate repair by double opposing Z-plasty. Plast Reconstr Surg. 1986;78(6):724-38. https://doi.org/10.1097/00006534-198678060-00002.

15. Ekin O, Calis M, Kulak Kayikci ME, Icen M, Gunaydin RO, Ozgur F. Modified superior-based pharyngeal flap is effective in treatment of velopharyngeal 
insufficiency regardless of the preoperative closure pattern. J Craniofac Surg. 2017;28(2):413-7. https://doi.org/10.1097/SCS.0000000000003328.

16. Henningsson G, Kuehn DP, Sell D, Sweeney T, Trost-Cardamone JE, Whitehill $T L$, et al. Universal parameters for reporting speech outcomes in individuals with cleft palate. Cleft Palate Craniofac J. 2008;45(1):1-17. https://doi.org/1 $0.1597 / 06-086.1$

17. Handa Y, Maeda K, Toida M, Kitajima T, Ishimaru J, Nagai A, et al. Kabuki make-up syndrome (Niikawa-Kuroki syndrome) with cleft lip and palate. J Craniomaxillofac Surg. 1991;19(3):99-101. https://doi.org/10.1016/S1010-51 82(05)80570-0.

18. Burke LW, Jones MC. Kabuki syndrome: underdiagnosed recognizable pattern in cleft palate patients. Cleft Palate Craniofac J. 1995;32(1):77-84. https://doi.org/10.1597/1545-1569_1995_032_0077_ksurpi_2.3.co_2.

19. Banka S, Veeramachaneni R, Reardon W, Howard E, Bunstone S, Ragge N, et al. How genetically heterogeneous is kabuki syndrome?: MLL2 testing in 116 patients, review and analyses of mutation and phenotypic spectrum. Eur J Hum Genet. 2012;20(4):381-8. https://doi.org/10.1038/ejhg.2011.220.

20. Kurahashi N, Miyake N, Mizuno S, Koshimizu E, Kurahashi H, Yamada K, et al. Characteristics of epilepsy in patients with kabuki syndrome with KMT2D mutations. Brain Dev. 2017;39(8):672-7. https://doi.org/10.1016/j.braindev.2 017.03.025.

21. Upton S, Stadter CS, Landis P, Wulfsberg EA. Speech characteristics in the kabuki syndrome. Am J Med Genet A. 2003;116A(4):338-41. https://doi.org/1 0.1002/ajmg.a.10039.

22. Parisi L, Di Filippo T, Roccella M. Autism spectrum disorder in kabuki syndrome: clinical, diagnostic and rehabilitative aspects assessed through the presentation of three cases. Minerva Pediatr. 2015;67(4):369-75.

23. Lehman N, Mazery AC, Visier A, Baumann C, Lachesnais D, Capri Y, et al. Molecular, clinical and neuropsychological study in 31 patients with kabuki syndrome and KMT2D mutations. Clin Genet. 2017;92(3):298-305. https:// doi.org/10.1111/cge.13010.

24. Lohmander A, Willadsen E, Persson C, Henningsson G, Bowden M, Hutters B. Methodology for speech assessment in the Scandcleft project--an international randomized clinical trial on palatal surgery: experiences from a pilot study. Cleft Palate Craniofac J. 2009;46(4):347-62. https://doi.org/10.1 597/08-039.1.

25. D'Antonio LL, Eichenberg BJ, Zimmerman GJ, Patel S, Riski JE, Herber SC, et al. Radiographic and aerodynamic measures of velopharyngeal anatomy and function following Furlow Z-plasty. Plast Reconstr Surg. 2000;106(3): 539-49; discussion 550-533. https://doi.org/10.1097/00006534-20000901000002.

26. Dudas JR, Deleyiannis FW, Ford MD, Jiang S, Losee JE. Diagnosis and treatment of velopharyngeal insufficiency: clinical utility of speech evaluation and videofluoroscopy. Ann Plast Surg. 2006;56(5):511-7; discussion 517. https://doi.org/10.1097/01.sap.0000210628.18395.de.

27. Mehendale FV, Birch MJ, Birkett L, Sell D, Sommerlad BC. Surgical management of velopharyngeal incompetence in velocardiofacial syndrome. Cleft Palate Craniofac J. 2004;41(2):124-35. https://doi.org/10.1 597/01-110.

28. DA LL, Davio M, Zoller K, Punjabi A, Hardesty RA. Results of Furlow Z-plasty in patients with velocardiofacial syndrome. Plast Reconstr Surg. 2001;107(4): 1077-9. https://doi.org/10.1097/00006534-200104010-00033.

29. Ysunza A, Pamplona MC, Molina F, Hernandez A. Surgical planning for restoring velopharyngeal function in velocardiofacial syndrome. Int J Pediatr Otorhinolaryngol. 2009;73(11):1572-5. https://doi.org/10.1016/j.jporl.2009.08. 007.

30. Chegar BE, Shprintzen RJ, Curtis MS, Tatum SA. Pharyngeal flap and obstructive apnea: maximizing speech outcome while limiting complications. Arch Facial Plast Surg. 2007;9(4):252-9. https://doi.org/10.1 001/archfaci.9.4.252.

31. Park M, Ahn SH, Jeong JH, Baek RM. Evaluation of the levator veli palatini muscle thickness in patients with velocardiofacial syndrome using magnetic resonance imaging. J Plast Reconstr Aesthet Surg. 2015;68(8):1100-5. https://doi.org/10.1016/j.bjps.2015.04.013.

\section{Publisher's Note}

Springer Nature remains neutral with regard to jurisdictional claims in published maps and institutional affiliations.

Ready to submit your research? Choose BMC and benefit from:

- fast, convenient online submission

- thorough peer review by experienced researchers in your field

- rapid publication on acceptance

- support for research data, including large and complex data types

- gold Open Access which fosters wider collaboration and increased citations

- maximum visibility for your research: over $100 \mathrm{M}$ website views per year

At BMC, research is always in progress.

Learn more biomedcentral.com/submissions 